\title{
A FORMAÇÃO EM PSICOLOGIA NO CONTEXTO DA DEMOCRATIZAÇÃO DO ENSINO SUPERIOR NO BRASIL
}

\author{
Fábio Henrique Dantas \\ Universidade Federal do Rio Grande do Norte - UFRN \\ Pablo Sousa Seixas \\ Universidade Federal do Rio Grande do Norte - UFRN \\ Oswaldo Hajime Yamamoto \\ Universidade Federal do Rio Grande do Norte - UFRN
}

\begin{abstract}
Resumo
O Ensino Superior no Brasil carrega uma estrutura que privilegia os interesses da burguesia e exclui estudantes oriundos das classes trabalhadoras. Assim, o elitismo que é um elemento marcante nas Universidades, caracterizou também a formação em Psicologia ao longo da história. Esse trabalho objetiva analisar o cenário da formação em Psicologia no Brasil no contexto da democratização do Ensino Superior. Para isso, foi realizada uma investigação com informações de domínio público localizadas em banco de dados do Ministério da Educação (MEC) e do Instituto Nacional de Pesquisas Educacionais Anísio Teixeira (INEP). Os principais resultados mostram que os cursos de Psicologia se distribuem geograficamente de forma heterogênea nas regiões brasileiras e que o perfil dos estudantes tem demonstrado mudanças concernentes às questões étnicas, ao número de alunos beneficiados por bolsas e financiamentos. Além disso, há o predomínio do curso noturno, o que pode supor que o curso de Psicologia seja composto majoritariamente por estudantes-trabalhadores e caracterizado por estudantes mulheres, brancas e jovens-adultas.
\end{abstract}

Palavras-chave: formação do Psicólogo; ensino superior; democracia; processos políticos.

\section{PSYCHOLOGY EDUCATION IN THE CONTEXT OF DEMOCRATIZATION OF HIGHER EDUCATION IN BRAZIL}

\begin{abstract}
The higher education in Brazil carries a structure that privileges the interests of the bourgeoisie and excludes students from the working-class. In this way, the elitism that is a striking element in the Universities, has also characterized Psychology Education throughout its history. Thus, this work aims to analyze the scenario of Psychology Education in Brazil, in the context of the democratization of Higher Education. For this, an investigation was carried out using public domain information located in a database of the Ministry of Education (MEC) and the National Institute of Educational Research Anísio Teixeira (INEP). The results show that Psychology courses are geographically distributed in a heterogeneous way in the Brazilian regions, and that the profile of the students has shown changes concerning ethnic issues, the number of students benefited by scholarships and financing, besides showing that the graduation in Psychology is constituted by student workers, female, white and young adult students. Keywords: Psychology training; higher education; democracy; political processes.
\end{abstract}




\title{
LA FORMACIÓN EN PSICOLOGÍA EN EL CONTEXTO DE LA DEMOCRATIZACIÓN DE LA ENSEÑANZA EN BRASIL
}

\begin{abstract}
Resumen
La Enseñanza Superior en el Brasil carga una estructura que privilegia los intereses de la burguesía y excluye estudiantes oriundos de las clases trabajadoras. De esa manera, el elitismo que es un elemento sobresaliente en las Universidades caracterizó también la formación en Psicología al largo de su historia. Así, ese trabajo pretende analizar el escenario de formación en Psicología en Brasil en el contexto de la democratización de la Enseñanza Superior. Para eso, fue realizada una búsqueda mediante informaciones de dominio público ubicadas en banco de datos del Ministerio de la Educación (MEC) del Instituto Nacional de Pesquisas Educacionales Anísio Texeira (INEP). Los resultados muestran que los cursos de Psicología se distribuyen geográficamente de forma heterogenia en las regiones brasileñas, y que el perfil de los estudiantes tiene demostrado cambios concernientes a las cuestiones étnicas, al número de alumnos beneficiados por becas y financiamientos, además de mostrar que la formación en Psicología es constituida por estudiantes trabajadores, estudiantes mujeres, blancas y jóvenes-adultas.

Palabras clave: formación en psicología; enseñanza superior; democracia; procesos políticos.
\end{abstract}

\section{INTRODUÇÃO}

O Ensino Superior no Brasil, ao longo da sua história, carrega consigo uma estrutura que privilegia os interesses da burguesia e exclui estudantes oriundos das classes trabalhadoras (Chauí, 2003). Nesse contexto, é importante compreender as contradições postas atualmente diante das políticas de educação atravessadas pela lógica neoliberal. E, para entender o atual projeto de Ensino Superior no Brasil, sob o discurso da democratização do acesso, é preciso situálo em sua totalidade histórica e como fruto de um processo social complexo, amplo e permeado por interesses de diversas ordens, costurado pela lógica do sistema capitalista.

Assim, as desigualdades de acesso ao Ensino Superior ainda representam um problema a ser resolvido na maioria dos países da América Latina, uma das regiões mais agravadas pela desigualdade de acesso à educação do mundo (Paula \& Lamarra, 2011). De fato, segundo esses autores, o Ensino Superior brasileiro estrutura-se como o mais privatizado e elitizado da América Latina. Nessa direção, as Instituições de Ensino Superior (IES) públicas apresentam um crescente aumento de estudantes com renda familiar mais elevada, ao mesmo tempo em que, cada vez menos, os estudantes trabalhadores, oriundos das classes populares, ingressam nesse sistema de ensino público. Isso significa que as condições socioeconômicas atreladas a questões geográficas, físicas e étnicoraciais são cada vez mais elementos que se relacionam com as condições de acesso e de permanência de estudantes em cursos superiores (Paula \& Lamarra, 2011).

O Brasil é um país continental e heterogêneo, com um amplo histórico de desigualdade e uma enorme assimetria social (Santos \& Silveira, 2001). Esses aspectos são reafirmados no âmbito educacional, uma vez que o acesso ao 
Ensino Superior, nesse país, tornou-se meritocrático e elitizado, apoiado num esquema seletivo, com número restrito de vagas que deve ser ocupadas por aqueles que obtivessem melhor desempenho em um teste. Tal processo rebate a falaciosa igualdade de condição entre os candidatos e atribui o ingresso na universidade unicamente aos critérios de competência e empenho individual, assim deixando de levar em conta uma série de discrepâncias e beneficiando um pequeno número de pessoas em detrimento da maioria (Corbucci, 2007).

Tal cenário demonstra como o elitismo é um elemento marcante na história de nossa sociedade e, nessa esteira, no Ensino Superior, a Psicologia, como ciência e profissão também foi atravessada e caracterizada como uma formação elitizada (Mello, 2010; Yamamoto, 2012). Desde sua origem, no fim do século XIX, a Psicologia construiu uma trajetória de produção científica e de fortalecimento das suas técnicas profissionais, de maneira indissociável do desenvolvimento do capitalismo. Pode-se dizer que o contexto que permitiu o nascimento da ciência psicológica é o mesmo que coloca a ciência sob a tutela do capital (Parker, 2014; Yamamoto, 1987).

No que concerne à formação em Psicologia, no final do século $X X$, as IES privadas eram responsáveis pela maioria dos psicólogos que concluíam o curso de graduação, ao passo em que o mercado já demonstrava dificuldades de absorver esses egressos. Tudo isso registra o fato de que a expansão e o acesso ao Ensino Superior fazem parte da agenda das políticas públicas desde a década de 1960, no setor público e privado, com foco na mercantilização do ensino, embora também seja fruto de lutas por uma educação pública, gratuita e de qualidade (Antunes, 2004).

Desde esse período, a educação superior estava associada à modernização do país e ao seu desenvolvimento social e econômico brasileiro, atendendo às demandas crescentes do capital internacional presentes no país. Na década de 1980, o país passou por uma abertura democrática e, posteriormente, nos anos iniciais da década de 1990, o processo de expansão do Ensino Superior se alinhou ao projeto neoliberal para esse nível de ensino, que tem o seu ápice no governo Fernando Henrique Cardoso (FHC). O período foi marcado pelo avanço desordenado das IES privadas e da desqualificação do ensino ofertado por elas; esse fator está também relacionado à falta de investimentos em pesquisas e aos baixos salários pagos aos docentes (Cunha, 2003).

Mais tarde, nos governos do Partido dos Trabalhadores (PT), o ensino superior se efetivou como um sistema de massa com a força das políticas de expansão (Gomes \& Moraes, 2012). Nesse período, em função das lutas populares e pressão de diversas entidades acadêmicas e profissionais, foram implementadas políticas que almejavam incluir e ampliar o acesso das classes trabalhadoras e minoritárias, que foram historicamente excluídas do acesso ao Ensino Superior. De acordo com Dourado (2003), a expansão do Ensino Superior no governo Lula se configura como uma política pública democrático-popular e se 
efetiva nas políticas de financiamento e de avaliação que impulsionam o desenvolvimento do Ensino Superior. Entretanto, mesmo no contexto de ampliação das Universidades Federais, vários estudos apontam a predominância das instituições privadas em detrimento das públicas (Paula \& Lamarra, 2011).

Ao analisar o cenário do Ensino Superior, por meio do amplo debate sobre as universidades desde o seu surgimento até os dias atuais, pode-se dizer que a democratização do acesso e a expansão das IES são discussões distintas, embora esta última seja um dos fatores que caracteriza e contribui na concretização da primeira. Nesse sentido, é possível afirmar, didaticamente, que a expansão diz respeito à construção e interiorização de novas IES, à ampliação de vagas e ao aumento quantitativo no número de matrículas, que já é uma realidade concreta no cenário do Ensino Superior brasileiro, conforme Paula e Lamarra (2011). Contudo, expandir o Ensino Superior não é sinônimo de sua democratização (Dias, 2010). A democratização do Ensino Superior está diretamente relacionada ao acesso da população historicamente excluída desse processo e, além disso, à programação de estratégias de permanência e qualidade de ensino para a classe. Ou seja, democratizar seria diminuir as desigualdades de acesso e permanência, levando em consideração as questões étnicas, sociais, econômicas, geográficas e de gênero.

Apesar da inegável expansão da rede pública federal e interiorização das IES no país, é visível o fortalecimento da privatização do Ensino Superior sob o discurso da democratização do acesso. Esse processo foi fortalecido pela ampliação de programas como o Programa de Financiamento Estudantil para cursos de graduação (FIES) (Vituri, 2014), pela criação do Programa Universidade Para Todos (PROUNI) (Martins, 2011) e pelo sistema de cotas (Mello, 2013).

Dessa forma, tudo isso repercutiu na formação em Psicologia como aponta o trabalho de Yamamoto, Souza, Silva e Zanelli (2010), na apresentação de dados atualizados referentes à expansão dos cursos de Psicologia no Brasil. De acordo com os autores, os cursos de Psicologia estavam, em sua maioria, em IES privadas, representando $89,1 \%$ do total de instituições, número superior à proporção de IES privadas no sistema de ensino que equivalia a $83,1 \%$.

Ainda por esse viés, é mister compreender o cenário da formação em Psicologia no contexto de expansão dos cursos de graduação, bem como de que modo a implementação das políticas de democratização do acesso atravessou a graduação em Psicologia nessa última década, numa tentativa contrahegemônica de democratizar o acesso. Torna-se, então, pertinente questionar: essa parcela da população que foi historicamente excluída do acesso ao Ensino Superior passa, por meio das políticas de democratização, a ter contato com a formação em Psicologia? Em outras palavras, pode-se indagar: as políticas de democratização dos últimos dez anos contribuíram para uma possível "deselitização" da formação em Psicologia? Dessa forma, esse trabalho objetiva 
analisar o cenário da formação graduada em Psicologia no Brasil, no contexto da atual expansão e das políticas de democratização do Ensino Superior.

\section{MÉTODO}

Para atender ao objetivo do presente trabalho, propõe-se uma investigação de abordagem quantitativa, realizada por meio de informações de domínio público, dados gerais sobre o Ensino Superior no país, localizados em bancos do Ministério da Educação (MEC) e do Instituto Nacional de Pesquisas Educacionais Anísio Teixeira (INEP). A razão de buscar esses bancos reside no fato de serem as principais fontes de obtenção de informações sobre o Ensino Superior no país, requisito fundamental para analisar o cenário da atual formação em Psicologia. A temporalidade dessa coleta retrata o ápice do cenário da expansão quantitativa dos cursos de Ensino Superior, em que estes foram ampliados sob o discurso da democratização do acesso nos últimos governos do PT.

Assim, o trabalho com os bancos foi dividido em blocos: no primeiro, a partir dos dados coletados, foram realizadas leituras exaustivas do banco de dados do censo do Ensino Superior (ano de 2014), o qual permitiu o acesso a informações diversas sobre os cursos de Psicologia no Brasil (quantidade de IES, categoria acadêmica, número de matriculados, número de trancamentos, etc.).

O segundo bloco de trabalho, se deu com o cadastro de instituições de Ensino Superior (e-MEC) permitiu, por meio da consulta avançada das IES do Brasil, acessar informações sobre todos os cursos de Psicologia em funcionamento no ano de 2016, além de identificar a distribuição geográfica dos cursos no processo de expansão. Assim, foi formado um banco de dados contendo informações referentes a todos os cursos de Psicologia no Brasil, organizados por região e por estado.

Esse questionário foi transferido para um software de análise quantitativa, e em seguida, foram realizadas estatísticas descritivas simples que possibilitaram o desenho do perfil desses estudantes de Psicologia. No terceiro bloco, foi realizada a análise do questionário socioeconômico do ENADE 2012, respondido por 22.985 estudantes de Psicologia do Brasil. Foram descritos e analisados os dados referentes ao questionário socioeconômico para identificar o perfil desses estudantes. Esse conjunto de perguntas e alternativas de respostas é, na verdade, o instrumento de coleta de dados utilizados pelo ENADE e formulado com o objetivo de caracterizar o perfil socioeconômico dos estudantes brasileiros de Ensino Superior; no caso dessa pesquisa, foram separados os dados apenas dos estudantes dos cursos de Psicologia.

A partir da leitura exaustiva do referencial teórico relativo ao processo de democratização do Ensino Superior no Brasil, emergiram, a partir da literatura, quatro categorias consideradas lógicas ou fatores de democratização. Dessa 
forma, os dados foram organizados para atender a essas categorias de análise, a primeira delas tratando da expansão do Ensino Superior; a segunda reúne dados relacionados ao sistema de bolsas e financiamentos que facilitaram a discussão do acesso dos estudantes a programas como o PROUNI e o FIES; a terceira diz respeito às questões étnicas dos estudantes. A quarta categoria trata do ensino noturno, a qual traz a discussão do estudante trabalhador, que foi também analisado por meio dos dados do questionário do ENADE.

A pesquisa foi desenvolvida em conformidade com a resolução no 510 do Conselho Nacional de Saúde (2016) sobre ética em pesquisa na área de ciências humanas e sociais.

\section{RESULTADOS E DISCUSSÃo}

\section{Caracterização geral da amostra}

A seguir, apresenta-se uma breve caracterização da amostra dessa pesquisa concernente ao perfil dos estudantes de Psicologia do Brasil. Dados que não são diretamente apontados pela literatura como fatores de democratização, contudo, são elementos que apontam indícios importantes sobre caminhos que poderão ser percorridos para se debater demandas emergentes à formação em Psicologia, assim como a busca de respostas acerca da possível deselitização dos cursos.

A faixa etária dos estudantes de Psicologia (dividida em categorias) demonstra que $58,5 \%$ dos alunos no Brasil estão na faixa etária de 22 a 27 anos. De acordo com Yamamoto, Falcão e Seixas (2011), no ano de 2006 esse grupo era constituído de $41,3 \%$, o que representa o aumento de $17,2 \%$ dessa faixa etária ingressante no Ensino Superior. O grupo de 28 a 85 anos que representam 40,2\% dos estudantes, em 2006 indicava 41,3\%, o que ainda representa uma formação adulta e jovem. Vale considerar que a divisão das categorias de faixa etária teve como base o padrão de alternativas do questionário socioeconômico do ENADE.

No que concerne ao sexo identificado no questionário do ENADE, a Psicologia no Brasil tem em sua maioria estudantes do sexo feminino: $82,6 \%$ de estudantes e $17,4 \%$ do sexo masculino, o que reforça o dado que a Psicologia ainda se constitui como uma profissão feminina. No que diz respeito ao estado civil de todos os estudantes de Psicologia os solteiros representam $71,7 \%$. O que define a formação em Psicologia como composta por mulheres, jovens e adultas e, em sua maioria, solteiras. Isso chama a atenção para a necessária discussão sobre gênero e trabalho feminino mediante a formação em Psicologia, tendo em vista ser uma profissão marcada por essas características. E, além deste fato, para os rebatimentos dessa profissão frente a uma sociedade machista e 
patriarcal, que submete a psicóloga brasileira a condições desiguais e precárias de trabalho (Lhullier, 2013).

No que diz respeito ao grau de escolaridade, $54,1 \%$ dos estudantes de Psicologia cursou todo, ou parte, do ensino médio em escola pública. Esse total, em 2006, representava 47,8\%, o que representa um aumento de 6,3 da quantidade de estudantes de Psicologia que estudaram o ensino médio em escolas públicas. Por outro lado, $43,2 \%$ dos estudantes tiveram a maior parte do seu ensino médio em escolas privadas. Os dados de 2006 indicavam um total de $48,4 \%$ dos estudantes, o que representa uma diminuição de 5,2\%. Pode-se dizer também que a maioria dos estudantes cursou o ensino médio tradicional $(81,1 \%)$. Nesse contexto, o aumento do acesso desses estudantes nas escolas públicas pode demonstrar um indício do processo de democratização da formação; contudo, vale levar em consideração a discussão de Mello (2013), ao alertar sobre o falacioso debate sobre o ensino público ser totalmente precário, ou seja, essa ascensão de vagas pode estar relacionada à elite do ensino público, localizada nos Institutos Federais e Colégios Militares. Já o grau de escolaridade dos pais desses estudantes, o número de pais com o Ensino Superior mantém-se em torno de 27 a 31\%, quando somado o quesito ensino superior e pósgraduação, ou seja, aproximadamente $70 \%$ dos pais não ingressaram no ensino superior, o que também representa uma pista sobre o nível socioeconômico dos estudantes.

De acordo com a resposta dos estudantes de Psicologia sobre a sua renda familiar, pode-se dizer que a população que ganha até 3 salários mínimos (incluindo os que não declararam nenhuma renda) aumentou em 9,5\%, conforme a comparação com os dados do último ENADE. Ao mesmo tempo, aqueles com renda familiar superior a 10 salários mínimos, diminuíram em $11,7 \%$, quando comparados ao último ENADE, o que pode representar um indício de deselitização dessa formação, quando se considera o fator renda. Apesar disto, vale considerar que a maioria dos estudantes está no grupo que declara renda familiar de 3 a 10 salários mínimos, representando o total de $51,6 \%$ no último ENADE, ou seja, a maioria.

\section{A expansão dos cursos}

O crescimento quantitativo dos cursos de Psicologia, assim como de outros cursos de graduação, é reflexo de um projeto de Ensino Superior que tem intensificado a expansão, interiorização e internacionalização do Ensino Superior. Atualmente, de acordo com censo da educação superior de 2014, há 2.368 IES do Brasil; destas, foram registradas 427 IES (18,03\%) que ofertam o curso de Psicologia. Diante do total geral de IES brasileiras, $298(12,58 \%)$ são IES públicas e $2070(87,41 \%)$ são privadas. Do total de IES que ofertam o curso de Psicologia, $76(17,79 \%)$ são IES públicas, enquanto que o número de IES privadas é quatro vezes maior, totalizando 351 IES privadas $(82,20 \%)$. 
Ainda no ano de 2014, de acordo com o censo, foram registrados 32.878 cursos de graduação, no Brasil, em diversas áreas. Desse número, o recorte de $11.036(33,56 \%)$ está nas IES públicas e $21.842(66,43 \%)$ fazem parte da rede privada. Nesse total geral da quantidade de cursos, 564 cursos são cursos de Psicologia e apenas 120 (21,27\%) deles se localizam em IES públicas; 444 $(78,72 \%)$ estão em IES privadas. Estudos como o de Yamamoto et al. (2011) apresentam dados de 2006 sobre a quantidade de cursos de Psicologia, que na época totalizavam 350; desses cursos, $89 \%$ estavam em IES da rede privada de ensino. Vale considerar que essa expansão rápida e desordenada como consideram Lisboa e Barbosa (2009), manifestou-se na considerada primeira fase da expansão do Ensino Superior e antes mesmo da implantação do Programa de Apoio a Planos de Reestruturação e Expansão das Universidades Federais (REUNI).

Esses cursos de Psicologia se distribuem geograficamente de forma bastante heterogênea nas regiões brasileiras e se multiplicaram em todos os estados brasileiros, entre o período de 2007, conforme os dados de Lisboa e Barbosa (2009), e 2016, conforme apresentado na Tabela 1. A exceção cabe a dois estados da região Norte: Roraima e Amapá, que permanecem com a mesma quantidade de cursos registrados em 2007, o primeiro estado com dois cursos de Psicologia $(0,32 \%)$ e o segundo com três cursos $(0,48 \%)$.

É importante salientar que a expansão quantitativa dos cursos de Psicologia não significa, necessariamente, que haja uma democratização dessa formação. Expandir não é sinônimo de democratizar (Dias, 2010). A expansão e a democratização são processos que estão interligados, tendo em vista que essa última depende da primeira, ou seja, a expansão é insuficiente para garantir a democratização, embora seja uma condição necessária. Assim, os dados demonstram uma expansão da Psicologia e uma promoção relativa da democratização dessa formação, levando-se em consideração apenas o aumento quantitativo do número de matrículas, a criação e interiorização de novas IES.

Em 2007, as regiões Sul e Sudeste somavam, sozinhas, 70,46\% dos cursos de Psicologia do país e, atualmente, elas totalizam 63,9\%. O mesmo aspecto dessa diminuição em termos percentuais foi percebido no estado de São Paulo, que detinha em 2007, o total de 26,26\% e, atualmente, 22,68\%. Essa diminuição da porcentagem de cursos na região Sudeste (mesmo com o aumento da quantidade de cursos implantados nos respectivos estados) reflete uma maior distribuição desses cursos nas demais regiões brasileiras.

Nesse aspecto, há um forte destaque para a região Nordeste, que superou todas as demais regiões brasileiras na abertura de cursos de Psicologia. Em 2007, o Nordeste detinha 15,4\% (61 cursos) do total de cursos de Psicologia do Brasil, e em 2016, essa porcentagem aumentou para 21,57\% (135 cursos). Bastos, Gondim e Rodrigues (2010) enfatizam os Estados do Rio Grande do Norte e Sergipe como os que estão abaixo da média nacional no que se refere ao 
número de ingressos nos cursos de Psicologia, o primeiro, que até o ano de 2007 contava com quatro cursos de Psicologia (Lisboa \& Barbosa, 2009). Atualmente, há um total de dez cursos, seis deles na capital do Estado e quatro localizados em cidades no interior do Estado, todas consideradas polos de desenvolvimento regional e polos regionais de saúde, sendo elas: Santa Cruz, Pau dos Ferros e Mossoró (com dois cursos).

Esse cenário representa um movimento de interiorização dos cursos de graduação no Brasil. A Psicologia, anteriormente, se caracterizava por ser uma formação urbana, localizada em sua maioria em centros urbanos e nas capitais nacionais. De acordo com Bastos, Gondim e Rodrigues (2010), esse movimento de interiorização se evidencia desde a década de 1970; entretanto, só no início dos anos 2000, o percentual de psicólogos que atuava no interior do país se aproxima do percentual dos que atuavam nas capitais.

O cenário da formação em Psicologia no Brasil, a partir do censo da educação superior de 2014, aponta que foram matriculados 7.828.013 estudantes em cursos de nível superior no Brasil, sendo que 207.070 (2,64\%) no curso de Psicologia. Desse último total, 27.176 (13,12\%) eram alunos que cursavam gratuitamente o curso, enquanto que os demais $179.894(86,87 \%)$ pagavam mensalidades ou eram beneficiados com algum tipo de bolsa ou financiamento proposto pelas políticas de democratização do acesso ao Ensino Superior.

Foram registrados 20.663 alunos que concluíram o curso de Psicologia em 2014, de acordo com o censo. Desse total, 4.037 (19,53\%) foram concluintes de IES públicas, e $16.626(80,46 \%)$ de IES privadas.

Diante dos $444(78,72 \%)$ cursos de Psicologia que foram implantados em IES privadas, 157 (35,36\%) estão em Universidades, 210 (47,29\%) em Faculdades e $77(17,34 \%)$ em Centros Universitários. De acordo com Yamamoto et al. (2010), 89,1\% dos cursos de Psicologia estavam em IES privadas, um número superior à média nacional de IES privadas, que representava $83,1 \%$. Esse avanço desordenado de IES privadas, que promoveu o avanço da formação em Psicologia no país, reflete o princípio da flexibilidade, que fundamentou a ampliação e a diversificação de modelos institucionais como centros universitários, faculdades integradas, faculdades isoladas e institutos superiores de educação (Gomes, Oliveira, \& Dourado, 2011).

É importante destacar que essa lógica de expansão é influenciada prioritariamente pela demanda mercadológica de Ensino Superior, e não pelas razões sociais, postas nos projetos pedagógicos, que justificam a criação dos cursos de Psicologia, como registra Seixas (2014). De acordo com Gomes et al. (2011), o mercado dita os rumos e as formas que as IES devem ser criadas e expandidas, guiando o sentido e o formato em que são constituídas as políticas de Ensino Superior. Essa competitividade mercantil, também transformou estudantes em consumidores de educação e mercantilizou as relações de 
poder/saber nas IES. A consequência disso é uma formação cada vez mais mercantilista, acrítica, reforçando a produção do conhecimento sob o controle do capital, servindo à iniciativa privada e, consequentemente, ao livre mercado (Chauí, 2003). No que concerne à formação em Psicologia, Botomé (2010) observa que a expansão desenfreada dos cursos de Psicologia aumentou em situação desproporcional a qualidades destes.

Tabela 1.

Distribuição geográfica dos cursos de graduação em Psicologia, no Brasil, nos anos 2007 e 2016

\begin{tabular}{|c|c|c|c|c|}
\hline \multirow{2}{*}{ Estado } & \multicolumn{2}{|c|}{$2007^{a}$} & \multicolumn{2}{|c|}{2016} \\
\hline & $\mathrm{N}$ & $\%$ & $\mathrm{~N}$ & $\%$ \\
\hline \multicolumn{5}{|c|}{ Sudeste } \\
\hline São Paulo & 104 & 26,26 & 142 & 22,68 \\
\hline Minas Gerais & 47 & 11,87 & 70 & 11,18 \\
\hline Rio de Janeiro & 31 & 7,83 & 41 & 6,55 \\
\hline Espírito Santo & 11 & 2,78 & 15 & 2,40 \\
\hline Total & 193 & 48,74 & 268 & 42,81 \\
\hline \multicolumn{5}{|c|}{ Sul } \\
\hline Rio Grande do Sul & 33 & 8,33 & 51 & 8,15 \\
\hline Paraná & 27 & 6,82 & 42 & 6,71 \\
\hline Santa Catarina & 26 & 6,57 & 39 & 6,23 \\
\hline Total & 86 & 21,72 & 132 & 21,09 \\
\hline \multicolumn{5}{|c|}{ Nordeste } \\
\hline Bahia & 22 & 5,56 & 42 & 6,71 \\
\hline Pernambuco & 12 & 3,03 & 21 & 3,35 \\
\hline Ceará & 6 & 1,52 & 24 & 3,83 \\
\hline Alagoas & 4 & 1,01 & 8 & 1,28 \\
\hline Paraíba & 4 & 1,01 & 10 & 1,60 \\
\hline Rio Grande do Norte & 4 & 1,01 & 9 & 1,44 \\
\hline Piauí & 4 & 1,01 & 9 & 1,44 \\
\hline Sergipe & 3 & 0,76 & 6 & 0,96 \\
\hline Maranhão & 2 & 0,51 & 6 & 0,96 \\
\hline Total & 61 & 15,4 & 135 & 21,57 \\
\hline \multicolumn{5}{|c|}{ Centro-Oeste } \\
\hline Goiás & 9 & 2,27 & 18 & 2,88 \\
\hline Mato Grosso do Sul & 8 & 2,02 & 10 & 1,60 \\
\hline Distrito Federal & 6 & 1,52 & 9 & 1,44 \\
\hline Mato Grosso & 6 & 1,52 & 15 & 2,40 \\
\hline Total & 29 & 7,32 & 52 & 8,31 \\
\hline
\end{tabular}




\begin{tabular}{ccccc}
\hline & \multicolumn{3}{c}{ Norte } & \\
Amazonas & 8 & 2,02 & 9 & 1,44 \\
Rondônia & 7 & 1,77 & 11 & 1,76 \\
Pará & 3 & 0,76 & 6 & 0,96 \\
Amapá & 3 & 0,76 & 3 & 0,48 \\
Tocantins & 2 & 0,51 & 5 & 0,80 \\
Roraima & 2 & 0,51 & 2 & 0,32 \\
Acre & 2 & 0,51 & 3 & 0,48 \\
\hline Total & 27 & 6,82 & 39 & 6,23 \\
\hline
\end{tabular}

a Os dados de 2007 foram extraídos de Lisboa e Barbosa (2009).

\section{Programa de bolsas e financiamentos}

De acordo com os estudantes que participaram do ENADE, ao serem questionados se recebem algum tipo de bolsa de estudos ou financiamentos para custear as mensalidades do curso, foi possível identificar o número de $12,8 \%$ de estudantes no Brasil que não recebem nenhum tipo de ajuda (pelo fato de estudarem em uma IES da rede pública). Assim, o total de $41,3 \%$ dos estudantes afirma receber algum tipo de bolsa ou financiamento e $45,8 \%$ afirmam não receber nenhum tipo de bolsa ou financiamento, mesmo estando em um curso não gratuito, conforme a Tabela 2. Ou seja, da população de 22985 estudantes de Psicologia do Brasil que responderam ao questionário socioeconômico do ENADE, 8760 estudantes afirmam receber algum tipo de bolsa ou financiamento para custear os seus estudos. Desse total, o recorte de $36,2 \%$ (8330 estudantes) respondeu ao quesito sobre a especificidade de que tipo de bolsa ou financiamento recebe para custear seus estudos.

Diante da amostra mencionada anteriormente, a média nacional aponta que $71,8 \%$ dos estudantes de Psicologia recebem algum tipo de bolsa e $28,2 \%$ têm algum tipo de financiamento. Desse total, 2,4\% dos estudantes recebem mais de um dos tipos de bolsa e financiamento citados nos parágrafos posteriores.

Do total dos $71,8 \%$ que recebem bolsas, $28,2 \%$ estão cadastrados no PROUNI (o que demonstra que a maioria dos estudantes beneficiados por bolsas recebe outro tipo de bolsa que não seja esse programa do governo federal). Contudo, em 2006, o número de estudantes de Psicologia cadastrados no PROUNI representava apenas 4,6\%, o que significa uma diferença de $23,6 \%$ de aumento dos alunos nesse programa.

Esse aumento de 23,6\%, comparado ao número de estudantes beneficiados no ano de 2006, representa uma ampliação do PROUNI nessa última década. Um programa que tem contribuído imensamente para o acesso da população de baixa renda ao Ensino Superior, inclusive em cursos que historicamente pertenciam às elites brasileiras. 
Embora promova em certa medida a democratização do acesso, os estudantes não têm, por meio do programa, garantia de condições de permanência nas IES, além de lidarem com problemas de ordem financeira no custeio dos estudos e questões de ordem acadêmica, como é o caso de estudantes que sentem dificuldades em algumas disciplinas em virtude de serem oriundos de uma educação básica deficitária (Martins, 2011). Esse programa, por outro lado, beneficia diretamente a expansão das IES privadas e alimenta a lógica da privatização do Ensino Superior, em virtude do benefício da isenção de uma imensa quantidade de impostos que as IES cadastradas deveriam pagar ao Estado; dinheiro que poderia ser investido na qualidade de ensino das IES públicas (Martins, 2011; Ribeiro \& Guzzo, 2017).

Diante do total de $28,2 \%$ dos estudantes que recebem financiamentos, $21,7 \%$ estão cadastrados no FIES. No ano de 2006 , esse número representava o total de $7,4 \%$, o que significa o aumento de $14,3 \%$ de estudantes que utilizaram esse crédito de financiamento. São beneficiados por financiamentos oferecidos pela própria instituição de ensino, 4,9\%; e 1,6\% são estudantes financiados por outras instituições como bancos privados.

O aumento de estudantes de Psicologia que utilizaram o FIES como crédito de financiamento representa uma ampliação quantitativa do acesso ao Ensino Superior. Tendo em vista que essa ampliação do acesso não necessariamente significa a permanência e a democratização desses estudantes nesses cursos, é inegável que, através do FIES, uma grande parcela de estudantes chegou aos cursos de Psicologia.

Esse dado sinaliza a possibilidade da realização do desejo de uma classe que foi historicamente excluída desse processo, e a partir disso, vislumbrou uma possibilidade de ingresso no mercado de trabalho - como também pode indicar um significativo endividamento desses estudantes, tendo em vista a inflexibilidade apontada nesse programa, além de ser mais um instrumento que visa promover a democratização do Ensino Superior, cujo modelo beneficia inteiramente a lógica do livre mercado, produzindo consumidores de educação (Vituri, 2014).

Tabela 2.

Quantidade de estudantes que recebem bolsas de estudos ou financiamentos

Concessão de bolsas de estudos ou financiamentos

N $\quad \%$

Sim, recebe bolsas de estudos ou financiamentos

$8760 \quad 41,3$

Não recebe bolsas de estudos ou financiamentos por estar em IES pública

$2717 \quad 12,8$

Não recebe nenhum tipo de bolsa ou financiamento estando em IES privada

971145,8 


\begin{tabular}{|c|c|c|}
\hline Total & 21188 & 100,0 \\
\hline Qual tipo de bolsa de estudos ou financiamentos & $\mathrm{N}$ & $\%$ \\
\hline PROUNI integral & 1557 & 18,7 \\
\hline Mais de um dos tipos de bolsa ou financiamento citados & 200 & 2,4 \\
\hline PROUNI parcial & 586 & 7,0 \\
\hline FIES & 1596 & 19,2 \\
\hline PROUNI Parcial e FIES & 207 & 2,5 \\
\hline $\begin{array}{l}\text { Outro tipo de bolsa oferecido por governo estadual, distrital ou } \\
\text { municipal }\end{array}$ & 802 & 9,6 \\
\hline $\begin{array}{c}\text { Bolsa integral ou parcial oferecida pela própria instituição de } \\
\text { ensino }\end{array}$ & 2402 & 28,8 \\
\hline $\begin{array}{l}\text { Bolsa integral ou parcial oferecida por outra entidade (empresa, } \\
\text { ONG, etc.) }\end{array}$ & 436 & 5,2 \\
\hline Financiamento oferecido pela própria instituição de ensino & 408 & 4,9 \\
\hline $\begin{array}{l}\text { Financiamento oferecido por outra entidade (banco privado, } \\
\text { etc.) }\end{array}$ & 136 & 1,6 \\
\hline Total & 8330 & 100,0 \\
\hline
\end{tabular}

\section{A identificação étnica dos estudantes}

Os estudantes de Psicologia, em sua maioria, se identificam como estudantes de cor branca $(66,3 \%)$, seguidos dos pardos e mulatos, que soma o total de $25,3 \%$. Os demais se identificam como negros $(6,0 \%)$; amarelo (origem oriental) totalizando $1,6 \%$ e indígenas com $0,8 \%$. Ou seja, mesmo somando o total de negros, pardos, mulatos e índios (32,1\%), pode-se dizer que a formação graduada em Psicologia no Brasil ainda é uma formação branca, tendo em vista a soma das demais etnias ser bem menor que o total de estudantes brancos, como pode ser verificado na Tabela 3. Embora a formação ainda seja caracterizada por estudantes brancos, percebe-se um aumento de estudantes negros, pardos e mulatos ao se estabelecer comparação com os estudantes que responderam ao questionário socioeconômico do ENADE 2006.

Nesse referido ano, a soma da quantidade de estudantes negros, pardos e mulatos equivale a um total de $23,6 \%$ de estudantes. Atualmente esses estudantes somam o total de $31,3 \%$, registrando um aumento de $7,7 \%$. Nesse 
sentido, os estudantes que se declararam brancos, que representavam $73,2 \%$ dos estudantes em 2006, hoje são 66,3\%, uma diminuição de 6,9\%, o que demonstra um aumento no perfil e, consequentemente, um indício de democratização dessa formação, considerando que o processo de democratização é caracterizado pela ampliação do acesso às populações historicamente excluídas desse processo, levando em consideração também as questões étnico-raciais (Sobrinho, 2010; Paula \& Lamarra, 2011).

No panorama nacional, de acordo com a Pesquisa Nacional por Amostra de Domicílios, feita pelo IBGE (2013), em 2012 (ano em que os estudantes responderam ao questionário socioeconômico), 46,2\% dos brasileiros eram brancos, $52,9 \%$ se identificavam como pardos ou negros, um dado que torna desproporcional a distribuição étnica atrelado ao acesso dessa população ao Ensino Superior, o que reforça uma questão estrutural relacionada à dívida histórica que a nação construiu com a população negra.

Essa diminuição do número de estudantes brancos e o aumento do número de estudantes negros, pardos e mulatos representa uma mudança significativa no perfil do estudante de Psicologia, além de ser um possível efeito das políticas de ação afirmativa, em especial do sistema de cotas, considerando que o acesso aos cursos de graduação era privilégio dos homens e mulheres brancos da elite brasileira. Nesse sentido, vale destacar que a implantação dessas políticas foi efeito da luta do Movimento Social Negro, nas últimas décadas, que tem construído uma agenda programática, cuja resposta se manifestou na implementação das politicas de ação afirmativa no governo Lula (Presidência da República, Casa Civil, Subchefia para Assuntos Jurídicos, 2012).

Assim, conforme Marques (2010), o sistema de cotas é uma importante alternativa de promoção à equidade, além de ser um instrumento de reparação da herança de exclusão do acesso à educação superior para população negra, que atravessa a formação social brasileira. Conforme a pesquisa dessa autora, a política de cotas é uma das únicas alternativas de inclusão/acesso da população negra ao Ensino Superior.

Ao analisar as especificidades da distribuição étnica dos estudantes por região, foram identificados alguns quadros que se distanciam da realidade nacional: em algumas regiões brasileiras é necessário somar o número de negros, pardos e mulatos para verificar que os estudantes da graduação em Psicologia são estudantes de origens étnicas demarcadas, em sua maioria, por não brancos, o que se distancia dos números apresentados na média nacional apontados anteriormente. É o caso da região Norte, que tem em seu perfil $51,2 \%$ de estudantes pardos e mulatos e 5,8\% de estudantes negros, o que totaliza $57 \%$ dos estudantes de Psicologia que se identificam na cor não branca, e isso caracteriza uma forte mudança no perfil do estudante de Psicologia.

Por sua vez, a região Nordeste também segue nesse sentido, com 42,5\% de estudantes pardos e mulatos e com $9,7 \%$ de estudantes negros, o que 
totaliza 52,2\% de estudantes de cor não branca. Esses números refletem a proporcionalidade de como a população dessas regiões se identifica em sua etnia. As regiões Norte e Nordeste são as regiões que se destacam, de acordo com o PNAD (IBGE, 2013), por sua população se caracterizar, em sua maioria, como preta ou parda: a região Norte $70,2 \%$ de pardos e $6,2 \%$ de negros e $22,0 \%$ de população branca. Já a região Nordeste, com $62,5 \%$ de pardos, $9,3 \%$ de negros e $27,7 \%$ de brancos.

O resultado dessa mudança no perfil étnico do estudante de Psicologia, também retoma uma demanda histórica da ciência psicológica com a população negra. De acordo com Munanga (2014), o racismo rebate na Psicologia e reverbera em demandas tanto para a Psicologia Clínica como para a Psicologia Social. Segundo o autor, essa última tem se distanciado desse debate, que há muito, já é objeto de estudos das ciências sociais.

Tabela 3.

Identificação étnica dos estudantes por região

\begin{tabular}{|c|c|c|c|}
\hline Região & Identificação étnica & $\mathrm{N}$ & $\%$ \\
\hline \multirow{6}{*}{ Norte } & Branco & 449 & 37,6 \\
\hline & Negro & 69 & 5,8 \\
\hline & Pardo/mulato & 612 & 51,2 \\
\hline & Amarelo (origem oriental) & 33 & 2,8 \\
\hline & Indígena & 32 & 2,7 \\
\hline & Total & 1195 & 100,0 \\
\hline \multirow{6}{*}{ Nordeste } & Branco & 1868 & 45,7 \\
\hline & Negro & 398 & 9,7 \\
\hline & Pardo/mulato & 1741 & 42,5 \\
\hline & Amarelo (origem oriental) & 43 & 1,1 \\
\hline & Indígena & 42 & 1,0 \\
\hline & Total & 4092 & 100,0 \\
\hline \multirow{6}{*}{ Sudeste } & Branco & 7214 & 70,8 \\
\hline & Negro & 620 & 6,1 \\
\hline & Pardo/mulato & 2132 & 20,9 \\
\hline & Amarelo (origem oriental) & 165 & 1,6 \\
\hline & Indígena & 58 & 6 \\
\hline & Total & 10189 & 100,0 \\
\hline \multirow{5}{*}{ Sul } & Branco & 3485 & 87,8 \\
\hline & Negro & 86 & 2,2 \\
\hline & Pardo/mulato & 328 & 8,3 \\
\hline & Amarelo (origem oriental) & 52 & 1,3 \\
\hline & Indígena & 18 &, 5 \\
\hline
\end{tabular}




\begin{tabular}{cccc} 
& Total & 3969 & 100,0 \\
\cline { 2 - 4 } & Branco & 1068 & 59,3 \\
Nentro-Oeste & 108 & 6,0 \\
& Pardo/mulato & 571 & 31,7 \\
& Amarelo (origem oriental) & & 1,5 \\
& Indígena & & 1,5 \\
\cline { 2 - 4 } & Total & & 100,0 \\
\hline
\end{tabular}

Ensino noturno: a discussão do estudante trabalhador

O total de 52,3\% dos estudantes de Psicologia, no Brasil, por meio do questionário respondido no ENADE, afirma que o curso se concentra no turno noturno. Esse número, em 2006, correspondia a 43,3\% (Yamamoto et al., 2011), ou seja, nesse intervalo de tempo, há um aumento de $9 \%$ de estudantes de Psicologia nesse turno, o que demonstra que a formação em Psicologia tem, possivelmente, ampliado cada vez mais o ingresso do estudante trabalhador.

Nesse cenário, apenas $24,5 \%$ afirmam que o curso se concentra no turno matutino (diurno); $13,2 \%$ no turno diurno (de forma integral); $7,4 \%$ no turno vespertino; e 2,7 dizem que os estudos não têm predominância em nenhum dos turnos.

O dado aponta que mais da metade dos cursos em Psicologia está no turno noturno. Isso permite olhar para esses cursos, sob a perspectiva de pensar uma formação para o estudante trabalhador. De acordo com Mesquita (2010) esse cenário aponta uma demanda histórica de trabalhadores que enxergavam, no turno noturno, a única possibilidade de ingresso na educação superior. Isso implica dizer que, nas últimas décadas, o Ensino Superior noturno tem se concretizado numa modalidade de democratização do acesso que tem gerado algumas inquietações relacionadas às condições de acesso, permanência e qualidade de ensino ofertada ao estudante trabalhador (Terribili, 2007).

Além disso, esse estudante submete-se a uma jornada dupla de trabalho e enfrenta o terceiro turno de trabalho nas IES que ofertam o seu curso de graduação à noite. Esse estudante vivencia, de acordo com Terribili (2007), inúmeras dificuldades para manter-se no seu curso de formação. Tais dificuldades vão desde a questão de alimentação inadequada e precariedade do transporte público, o que compromete diretamente o seu desempenho nas disciplinas, ao atraso nas aulas e à falta nas avaliações. Segundo o autor, não há políticas públicas, nem institucionais que assegurem direitos ao estudante trabalhador, nem que assegurem também o cuidado das suas condições de trabalho/estudo, levando em consideração o estresse e o cansaço que vivenciam cotidianamente. 
Tudo isso gera demandas para a formação em Psicologia, tendo em vista o número significativo de estudantes que são submetidos a essas condições de acesso ao Ensino Superior noturno. É importante considerar, ainda, o processo de ensino e aprendizagem desses estudantes que, além de muitas vezes não terem a qualidade de ensino ofertada, acabam prejudicados na sua condição de estudo/trabalho devido à sobrecarga de atividades em seu cotidiano.

\section{CONSIDERAÇÕES FINAIS}

É necessário considerar a democratização como um fenômeno multifacetado, que não depende exclusivamente do avanço de um ou outro fator como a política de expansão, ações afirmativas ou a implementação dos programas de bolsas e financiamentos. Nesse sentido, não se pode garantir que esses fatores democratizaram a formação em Psicologia, embora, eles apontam indícios efetivos de um processo de transformação do perfil da formação e dos estudantes.

Assim, ainda há um longo caminho a se percorrer no que tange a democratização das Universidades. Sobretudo, porque, faz-se mister reconhecer que há um projeto de ensino superior no Brasil que atende e privilegia um modelo de democratização que tem percorrido e beneficiado a lógica das das IES privadas em detrimento das públicas. Uma lógica que se veste no discurso da democratização do acesso e do princípio da equidade, mas transita, em absoluto, sob o formato de exploração neoliberal, refletida do modo de produção capitalista.

Contudo, vale considerar que o ensino superior brasileiro tem avançado no que diz respeito às políticas de inclusão e democratização do acesso. Esse quesito contraria o percurso histórico do ensino superior que durante décadas delimitava o acesso a classes sociais específicas, concentrando a formação nos centros urbanos e capitais do Brasil. Esse fenômeno tem suas consequências na formação em Psicologia, com a ampliação de cursos de forma desenfreada, como aponta Botomé (2010).

Atualmente, essa formação caracteriza-se por ser feminina, de jovens adultas, brancas e em sua maioria solteiras. Entretanto vale ressaltar que as políticas de democratização expandiram e interiorizaram os cursos em, praticamente, todas as regiões do país. Diante disso, pode-se dizer que esse movimento democratizou a distribuição de cursos no território brasileiro à medida que aumentaram a criação de cursos nas regiões Norte e Nordeste, em detrimento da região Sudeste. A consequência disso também se manifesta no número de estudantes matriculados e egressos nos cursos de Psicologia.

Esse processo de expansão também ocasionou uma mudança no perfil desse estudante, tendo em vista que aumentaram significativamente o número de alunos beneficiados por bolsas e financiamentos. Além disso, apesar da 
formação se caracterizar etnicamente como branca, nas regiões como a Norte e Nordeste, há um forte aumento do número de estudantes não brancos, que somam aproximadamente $50 \%$ desses. Um outro fator de democratização diz respeito à formação em Psicologia ser caracterizada pela presença de estudantes trabalhadores, que encontram na possibilidade do ensino noturno, uma alternativa de acesso ao ensino superior.

Desse modo, vale considerar que os avanços relativos a democratização do ensino superior, alcançados nesses últimos anos, estão sob risco. É preciso demarcar o ensino superior e a formação em Psicologia na atual conjuntura de retração de direitos postos pelo Governo Temer. Esse retrocesso teve seu ponto de partida mediante a Proposta de Emenda Constitucional (PEC) 55 (Câmara dos Deputados, 2016), cujo objetivo é o congelamento dos orçamentos destinados a Educação, pondo em ameaça o prosseguimento dos programas aqui debatidos. Somam-se a isso as propostas reformistas que tem beneficiado a burguesia brasileira em detrimento da classe trabalhadora.

Ademais, algumas indagações se fazem pertinentes mediante as considerações desse cenário. As mesmas podem refletir os rebatimentos da mudança desse perfil de estudante e os caminhos que percorrerá a formação em Psicologia nas próximas décadas, além de servir de base para outros estudos acerca desse objeto: o fato de essa parcela da população, historicamente excluída, ingressar nos cursos de Psicologia poderá trazer algum impacto no que concerne a um profissional mais competente, ética e tecnicamente, com a sua classe, conforme aponta Yamamoto (2012)? De que forma uma Psicologia democratizada no ensino implicaria na "deselitização" não apenas da população de estudantes e de profissionais Psicólogos, mas também no tipo de conhecimento e trabalho que desenvolvem junto à sociedade?

\section{DECLARAÇÃO DE CONFLITO DE INTERESSES}

Os autores declaram que não há conflito de interesses.

\section{REFERÊNCIAS}

Antunes, M. A. M. (2004). A psicologia no Brasil no século XX: Desenvolvimento científico e profissional. In M. Massimi \& M. C. Guedes (Eds.), História da psicologia no Brasil: Novos estudos (pp. 109-152). São Paulo, SP: EDUC/Cortez.

Bastos, A. V. B., Gondim, S. M. G., \& Rodrigues, A. (2010). Uma categoria profissional em expansão: quantos somos e onde estamos? In A. V. B. Bastos \& M. G. Gondim (Eds.), O trabalho do psicólogo no Brasil (pp. 3244). Porto Alegre, RS: Artmed. 
Botomé, S. P. A. (2010). Quem nós, psicólogos, servimos de fato? In 0. Yamamoto \& A. L. Costa (Eds.), Escritos sobre a profissão de psicólogo no Brasil (pp. 141-162). Natal, RN: EDUFRN. (Texto original publicado em 1979).

Câmara dos Deputados. (2016). Proposta de Emenda à Constituição no 55. Brasília, DF.

Chauí, M. (2003). A universidade pública sob nova perspectiva. Revista Brasileira de Educação, 24, 5-15. doi:10.1590/S1413-24782003000300002

Corbucci, P. R. (2007). Desafios da educação superior e desenvolvimento no Brasil (Texto para discussão n. 1287). Recuperado em 14 março 2018, do Instituto de Pesquisa Econômica Aplicada

[IPEA] http://www.ipea.gov.br/portal/images/stories/PDFs/TDs/td_1287.pdf

Cunha, L. A. (2003). O Ensino Superior no octênio FHC. Educação \& Sociedade, 24(82), 37-61. doi:10.1590/S0101-73302003000100003

Dias, S. J. (2010). Democratização, qualidade e crise da educação superior: Faces da exclusão e limites da inclusão. Educação \& Sociedade, 31(113), 1223-1245. doi:10.1590/S0101-73302010000400010

Dourado, L. F. (2003, 7 de janeiro). Lula e a educação superior pública no Brasil. Jornal O Popular.

Gomes, A. M., \& Moraes, K. N. (2012). Educação superior no Brasil contemporâneo: Transição para um sistema de massa. Educação \& Sociedade, 33(118), 171-190. doi:10.1590/S0101-73302012000100011

Gomes, A. M., Oliveira, J. F., \& Dourado, L. F. (2011). Políticas de educação superior no Brasil. In M. F. C. Paula \& N. F. Lamarra (Eds.), Reformas e democratização da educação superior no Brasil e na América Latina (pp. 153-190). São Paulo, SP: Ideias \& Letras.

Instituto Brasileiro de Geografia e Estatística. (2013). Pesquisa nacional por amostra de domicílios: Síntese de indicadores 2012. Rio de Janeiro, RJ: Autor.

Lhullier, L. A. (2013). Quem é a psicologia brasileira? Mulher, psicologia e trabalho. Brasília, DF: Conselho Federal de Psicologia.

Lisboa, F. S., \& Barbosa, A. J. G. (2009). Formação em Psicologia no Brasil: Um perfil dos cursos de graduação. Psicologia: Ciência e Profissão, 29(4), 718737. doi: $10.1590 / S 1414-98932009000400006$

Marques, E. P. S. (2010). O Programa Universidade para Todos e a inserção de negros na educação superior: $A$ experiência de duas instituições de educação superior de Mato Grosso do Sul - 2005 - 2008 (Tese de doutorado). Recuperado de https://repositorio.ufscar.br/handle/ufscar/2244

Martins, R. M. A. (2011). PROUNI: Uma política de democratização do ensino superior? (Dissertação de mestrado). Recuperado de http://locus.ufv.br/handle/123456789/3421 
Mello, M. R. M. (2013). Cotas sociorraciais em universidades (Dissertação de mestrado). Recuperado

http://www.repositorio.ufal.br/handle/riufal/1250

Mello, S. L. (2010). Psicologia: Características da Profissão. In O. Yamamoto \& A. L. Costa (Eds.), Escritos sobre a profissão de psicólogo no Brasil (pp. 141162). Natal, RN: EDUFRN. (Texto original publicado em 1975)

Mesquita, M. C. G. D. (2010). O trabalhador estudante do ensino superior noturno: possibilidades de acesso, permanência com sucesso e formação (Tese de doutorado). Recuperado de http://tede2.pucgoias.edu.br:8080/handle/tede/677

Munanga, K. (2014). Prefácio. In I. Carone \& M. A. S. Bento (Eds.), Psicologia social do racismo: Estudos sobre branquitude e branqueamento no Brasil (pp. 9-11). Petrópolis, RJ: Vozes.

Parker, I. (2014). Revolução na Psicologia: Da alienação à emancipação. Campinas, SP: Alínea.

Paula, M. F. C., \& Lamarra, N. F. (2011). Reformas e democratização da educação superior no Brasil e na América Latina. São Paulo, SP: Ideias \& Letras.

Presidência da República, Casa Civil, Subchefia para Assuntos Jurídicos. (2012). Lei no 12.711. Brasília, DF.

Ribeiro, F. M., \& Guzzo, R. S. L. (2017). Consciência de estudantes prounistas sobre sua inserção no ensino superior. Psicologia: Ciência e Profissão, 37(2), 418-431. doi:10.1590/1982-3703001472016

Santos, M., \& Silveira, M. L. (2001). O Brasil: Território e Sociedade no Início do Século XXI. São Paulo, SP: Record.

Seixas, P. S. (2014). A formação graduada em Psicologia no Brasil: Reflexão sobre os principais dilemas em um contexto Pós-DCN (Tese de doutorado). Recuperado de http://repositorio.ufrn.br/jspui/bitstream/123456789/17401/1/PabloSS_TE SE.pdf

Terribili, A., Filho. (2007). Educação superior no período noturno: Impacto do entorno educacional no cotidiano do estudante (Tese de doutorado). Recuperado de https://repositorio.unesp.br/handle/11449/104842

Vituri, R. C. I. (2014). Fundo de Financiamento Estudantil (Fies) para o ensino superior privado: Acesso, processos e contradições (Dissertação de mestrado). Recuperado de https://tede2.pucsp.br/handle/handle/9808

Yamamoto, O. H. (1987). A crise e as alternativas da psicologia. São Paulo, SP: EDICON.

Yamamoto, O. H. (2012). 50 anos de profissão: Responsabilidade social ou projeto ético-político. Psicologia: Ciência e Profissão, 32(número especial), 6-17. doi:10.1590/S1414-98932012000500002 
Yamamoto, O. H., Falcão, J. T. R., \& Seixas, P. S. S. (2011). Quem é o estudante de psicologia do Brasil? Avaliação Psicológica, 10(3), 209-232. Recuperado em 14 março 2018, de http://pepsic.bvsalud.org/scielo.php?script=sci_arttext\&pid=S167704712011000300002

Yamamoto, O. H., Souza, J. A. J., Silva, N., \& Zanelli, J. C. (2010). A formação básica, pós-graduada e complementar do psicólogo no Brasil. In A. V. B. Bastos \& M. G. Gondim (Eds.), O trabalho do psicólogo no Brasil (pp. 4565). Porto Alegre, RS: Artmed.

Sobre os autores

Fábio Henrique Dantas é psicólogo, Mestre e doutorando em Psicologia pela Universidade Federal do Rio Grande do Norte. Professor do Departamento de Psicologia da Faculdade Evolução Alto Oeste Potiguar.

fabiohenriquefh@gmail.com

Pablo de Sousa Seixas é psicólogo, Mestre e Doutor pela Universidade Federal do Rio Grande do Norte. Professor adjunto da Universidade Federal do Rio Grande do Norte, campus Santa Cruz. pablo.seixas@hotmail.com

Oswaldo H. Yamamoto é psicólogo pela Pontifícia Universidade Católica de São Paulo, mestre em Educação pela Universidade Federal do Rio Grande do Norte e doutor em Educação pela Universidade de São Paulo. Professor titular da Universidade Federal do Rio Grande do Norte. oswaldo.yamamoto@gmail.com

A contribuição de cada autor pode ser atribuída como se segue:

F.D. contribuiu para conceitualização, investigação e redação inicial e final do artigo e P.S.S e O.Y. contribuíram com a conceitualização e redação final (revisão e edição).

Recebido em: 15/09/2017

$1^{a}$ revisão em: 20/12/2017

Aceito em: 31/05/2018 